\title{
Tinjauan Ketepatan Koding Penyakit Gastroenteritis Pada Pasien BPJS Rawat Inap di UPTD RSUD Kota Salatiga
}

\author{
Review of the Accuracy of Coding for Gastroenteritis in Inpatient BPJS Patients \\ in UPTD RSUD Kota Salatiga
}

\author{
Elise Garmelia'1) \\ Maulida Sholihah') \\ 1)Jurusan Rekam Medis dan Informasi Kesehatan; Poltekkes Kemenkes Semarang \\ Jl. Tirto Agung, Pedalangan, Banyumanik, Semarang \\ 2) RSUD Dr. Moewaardi Surakarta \\ Jl. Kolonel Sutarto o. 132, Jebres, Surakarta \\ Email:elsa0306@gmail.com, maulidasholihah10@gmail.com,
}

\begin{abstract}
One of the factors causing the inaccuracy of writing diagnosis code is sometimes doctors do not write the diagnosis in the complete form so that medical record errors occur in determining the diagnosis code. Based on preliminary studies that researchers have done in UPTD RSUD Salatiga, the researchers found the results of encoding gastroenteritis disease is inappropriate. Researchers took a random sample, from 8 medical records of patients with BPJS gastroenteritis inpatient there were 6 medical records showing the inaccuracy of encoding diagnosis with 75\% percentage of incorrect code and there was different writing of gastroenteritis diagnosis on admission discharge form and discharge summary form. The purpose of this study to determine the accuracy of coding disease gastroenteritis. The type of the research is descriptive quantitative research using cross sectional approach. The population in this research is medical record of inpatients of BPJS gastroenteritis case in january 2017 until october 2017, with the sample of 82 medical record by using simple random sampling method.The results showed the percentage of appropriateness of writing diagnosis on the outline forms form outgoing and returning home is $93.9 \%$, the percentage of accuracy of gastroenteritis disease code is $91.5 \%$ and the percentage of appropriateness of diagnosis with the result of laboratory examination is $89 \%$. Factors affecting the inaccuracy of coding results are that medical personnel (physicians) write incomplete and incompatible patients' diagnostic diagnosis of the form sheet, the coder does not check the results of the laboratory to determine the correct code, the lack of update activity of the ICD-10 coding latest version. Of these factors can affect the quality of medical records with the results of coding, claims results and analysis of hospital reporting data.
\end{abstract}

Keywords: ICD-10; Coding Gastroenteritis

\begin{abstract}
Abstrak
Salah satu faktor penyebab dari ketidaktepatan penulisan kode diagnosis adalah terkadang dokter tidak menuliskan diagnosis dengan lengkap sehingga terjadi kesalahan perekam medis dalam menentukan kode diagnosis. Berdasarkan studi pendahuluan yang telah peneliti lakukan di UPTD RSUD Kota Salatiga ditemukan hasil pengkodean penyakit gastroenteritis yang tidak tepat. Peneliti mengambil sampel secara random, dari 8 rekam medis pasien BPJS rawat inap penyakit gastroenteritis terdapat 6 rekam medis yang menunjukkan ketidaktepatan pengkodean diagnosis dengan persentase $75 \%$ kode tidak tepat dan terdapat perbedaan penulisan diagnosis gastroenteritis pada formulir ringkasan masuk keluar dan ringkasan pulang.Tujuan penelitian untuk mengetahui ketepatan koding penyakit gastroenteritis. Jenis penelitian yang digunakan adalah penelitian deskriptif kuantitatif dengan menggunakan pendekatan cross sectional. Populasi dalam penelitian ini adalah rekam medis rawat inap pasien BPJS kasus gastroenteritis pada bulan januari 2017 sampai bulan oktober 2017, dengan sampel 82 rekam medis dengan menggunakan metode simple random sampling. Hasil penelitian menunjukkan persentase kesesuaian penulisan diagnosis pada
\end{abstract}


lembar formulir ringkasan masuk keluar dan ringksan pulang 93,9\%, persentase ketepatan pemberian kode penyakit gastroenteritis $91,5 \%$ dan persentase kesesuaian penulisan diagnosis dengan hasil pemeriksaan laboratorium 89 \%. Faktor-faktor yang mempengaruhi ketidaktepatan hasil pengkodean adalah tenaga medis (dokter) menuliskan diagnosis gastroenteritis pasien secara tidak lengkap dan tidak sesuai antar lembar formulir, coder tidak mengecek hasil pemeriksaan penunjang (laboratorium) untuk menentukan kode yang tepat, kurangnya kegiatan update koding ICD-10 Versi terbaru. Dari faktor-faktor tersebut dapat mempengaruhi mutu rekam medis dengan hasil pengkodean, hasil klaim dan analisa data pelaporan rumah sakit.

Kata Kunci : ICD-10; Koding Gastroenteritis

\section{Pendahuluan}

Rumah Sakit menurut Undang - undang Republik Indonesia No. 44 Tahun 2009 (Pasal 1), Rumah Sakit adalah institusi pelayanan kesehatan yang menyelenggarakan pelayanan kesehatan perorangan secara paripurna yang menyediakan pelayanan rawat inap, rawat jalan, dan gawat darurat. Pelayanan kesehatan terhadap masyarakat perlu tercatat atau terekam sebagai dokumen penting yang bersifat rahasia yang dinamakan rekam medis.

Rekam Medis menurut Edna K Huffman adalab berkas yang menyatakan siapa, apa, mengapa, dimana, kapan dan bagaimana pelayanan yang diperoleh seorang pasien selama dirawat atau menjalani pengobatan. Rekam medis yang baik merupakan cerminan pelayanan kesehatan yang bermutu.

Berdasarkan Keputusan Menteri Kesehatan RI No. 377/MenKes/SK/III/ 2007 Tentang Standar Profesi Perekam Medis dan Informasi Kesehatan disebutkan bahwa kompetensi pertama dari seorang perekam medis adalah menentukan kode penyakit dan tindakan medis dalam pelayanan dan manajemen kesehatan. Acuan yang digunakan dalam pengkodean penyakit yaitu ICD-10 dan acuan pengkodean tindakan medis yaitu ICD-9 CM.

Peraturan Menteri Kesehatan Republik Indonesia Nomor 76 Tahun 2016 Tentang Pedoman Indonesia Case Base Groups (INACBG) dalam Pelaksanaan Jaminan Kesehatan Nasional disebutkan bahwa Jaminan Kesehatan Nasional adalah jaminan berupa perlindungan kesehatan agar peserta memperoleh manfaat pemeliharaan kesehatan dan perlindungan dalam memenuhi kebutuhan dasar kesehatan yang diberikan kepada setiap orang yang telah membayar iuran atau iuran yang dibayar oleh pemerintah. Dalam pemberlakuan Jaminan
Kesehatan Nasional, pengajuan pembiayaan kesehatan klaim pada INA-CBG's dengan menggunakan kode.

Salah satu faktor penyebab ketidaktepatan penulisan kode diagnosis terkadang dokter tidak menuliskan diagnosis dengan lengkap sehingga terjadi kesalahan perekam medis dalam menentukan kode diagnosis dan penyakit. Ketepatan koding penyakit dan tindakan medis penting dalam rekam medis pasien selain kelengkapan rekam medis yang bermutu, diagnosis juga diperukan dalam pelayanan medis lainnya.

Peraturan Menteri Kesehatan Republik Indonesia Nomor 5 Tahun 2014 Tentang Panduan Praktis Klinis (PPK) Bagi Dokter Di Fasilitas Pelayanan Kesehatan Primer, Gastroenteritis adalah peradangan mukosa lambung dan usus halus yang ditandai dengan diare, buang air besar lembek atau cair, dapat bercampur darah atau lendir dengan frekuensi 3 kali atau lebih dalam waktu 24 jam disertai muntah, demam, dan rasa tidak enak diperut.

UPTD RSUD Kota Salatiga merupakan Rumah Sakit bertipe B Pendidikan dan telah bekerjasama dengan BPJS Kesehatan dalam pelaksanaan Jaminan Kesehatan Nasional (JKN). Pada umumnya jenis pasien yang ada di UPTD RSUD Kota Salatiga adalah pasien BPJS yang melakukan pembayaran pelayanan kesehatan berdasarkan tarif yang ada pada software INA-CBG's. UPTD RSUD Kota Salatiga telah melaksanakan standar pengkodean dengan menggunakan ICD-10 dan ICD-9CM Versi 2010.

Dari sumber data yang ada di UPTD RSUD Kota Salatiga pada tahun 2017 diagnosis Gastroenteritis termasuk dalam daftar 10 besar penyakit pasien rawat inap dengan morbiditas tertinggi Berdasarkan studi pendahuluan yang 
telah peneliti lakukan di UPTD RSUD Kota Salatiga, didapatkan hasil observasi sebagai berikut : ditemukan hasil pengkodean penyakit gastroenteritis pada rekam medis pasien BPJS rawat inap yang tidak tepat/kurang spesifik dikarenakan tidak ada karakter ke-4 yang menjelaskan patologi penyakit gastroenteritis infeksi maupun non infeksi dan terdapat penentuan kode yang tidak sesuai dengan hasil pemeriksaan laboratorium. Peneliti mengambil sampel secara random, dari 8 rekam medis pasien BPJS rawat inap penyakit gastroenteritis terdapat 6 rekam medis yang menunjukkan ketidaktepatan pengkodean diagnosis dengan persentase $75 \%$ kode tidak tepat misalnya gastroenteritis acute dengan kode ICD-10 (A09) saja, selain itu terdapat penulisan diagnosis gastroenteritis yang kurang lengkap dan berbeda penulisan diagnosis pada lembar formulir ringkasan masuk keluar dan ringkasan pulang.

Dampak yang terjadi bila terdapat ketidaktepatan kode maupun ketidaksesuaian penulisan diagnosis akan berpengaruh pada turunnya mutu pelayanan serta mempengaruhi analisa data pelaporan dan ketepatan tarif INA-CBG's dalam pengantian biaya kepada pihak rumah sakit. Berdasarkan uraian diatas peneliti tertarik ingin mengambil judul "Tinjauan Ketepatan Koding Penyakit Gastroenteritis Pada Pasien BPJS Rawat Inap UPTD RSUD Kota Salatiga".

\section{Metode}

Jenis penelitian yang digunakan adalah penelitian deskriptif kuantitatif dengan pendekatan cross sectional yaitu variable sebab atau resiko dan akibat atau kasus yang terjadi pada objek penelitian yang diukur atau dikumpulkan secara simultan (dalam waktu yang bersamaan) (Notoatmodjo, 2010).

Waktu penelitian dilaksanakan pada bulan Januari - Mei 2018 di Instalasi Rekam Medis UPTD RSUD Kota Salatiga dengan 82 sampel rekam medis pasien BPJS rawat inap kasus GE dan melakukan wawancara dengan 2 petugas rekam medis bagian koding. Metode pengumpulan data menggunakan metode observasi dan wawancara. Analisis dilakukan dengan analisis statistik yang bersifat deskripsi.

\section{Hasil dan Pembahasan}

Ketepatan kode penyakit gastroenteritis di kelompokkan berdasarkan beberapa kriteria ketepatan yaitu kriteria kesesuaian penulisan diagnosis yang tertulis pada lembar formulir ringkasan masuk keluar dan ringkasan pulang, ketepatan pemberian kode gastroenteritis, kesesuaian hasil pemeriksaan laboratorium dengan penulisan diagnosis gastroenteritis serta faktor-faktor yang mempengaruhi ketepatan koding gastroenteritis.

\section{a. Kesesuaian Penulisan Diagnosis}

Gastroenteritis yang Tertulis Pada Lembar

Formulir Ringkasan Masuk Keluar dan Ringkasan Pulang

Dari sampel acak pasien gastroenteritis 2017 yang telah peneliti kelompokkan berdasarkan usia pasien gastroenteritis yang dirawat oleh DPJP dan berdasarkan jenis kelamin pasien yang menderita gastroenteritis dengan persentase sebagai berikut :

Tabel 1. Persentase Berdasarkan Usia Pasien Gastroenteritis Yang Dirawat Dokter Penanggungjawab Pasien

\begin{tabular}{|c|c|c|c|c|c|c|}
\hline \multirow[b]{2}{*}{ DPJP } & \multicolumn{4}{|c|}{ Usia Pasien } & \multirow[b]{2}{*}{$\left(\sum\right)$} & \multirow[b]{2}{*}{$(\%)$} \\
\hline & $\begin{array}{c}1-4 \\
\text { tahun }\end{array}$ & $\begin{array}{l}5-14 \\
\text { tahun }\end{array}$ & $\begin{array}{c}15-24 \\
\text { tahun }\end{array}$ & $\begin{array}{l}>25 \\
\text { tahun }\end{array}$ & & \\
\hline $\begin{array}{c}\text { Spesialis } \\
\text { Penyakit } \\
\text { Anak }\end{array}$ & 34 & 5 & - & - & 39 & $47,6 \%$ \\
\hline $\begin{array}{c}\text { Spesialis } \\
\text { Penyakit } \\
\text { Dalam }\end{array}$ & - & - & 12 & 31 & 43 & $52,4 \%$ \\
\hline & $\sum \mathrm{T}$ & otal Pas & & & 82 & $100 \%$ \\
\hline
\end{tabular}

Sumber : Data Primer Rekam Medis

Tabel 2. Persentase Berdasarkan Jenis Kelamin Pasien Gastroenteritis

\begin{tabular}{cccc}
\hline No & $\begin{array}{c}\text { Berdasarkan } \\
\text { Jenis Kelamin Pasien }\end{array}$ & $\left(\sum\right)$ & $(\boldsymbol{\%})$ \\
\hline 1. & Laki-laki & 44 pasien & $53,7 \%$ \\
2. & Perempuan & 38 pasien & $46,3 \%$ \\
\hline & $\sum$ Total & 82 pasien & $\mathbf{1 0 0} \%$ \\
\hline
\end{tabular}

Sumber : Data Primer Rekam Medis

Dari 82 sampel rekam medis didapatkan : 77 penulisan diagnosis pada rekam medis pasien gastroenteritis yang sesuai dan hanya ada 5 penulisan diagnosis gastroenteritis yang tidak sesuai antara lembar formulir ringkasan masuk keluar dan ringkasan pulang dengan persentase sebagai berikut : 
Tabel 3. Kesesuaian Penulisan Diagnosis Gastroenteritis pada Formulir Ringkasan Masuk Keluar dan Ringkasan Pulang

\begin{tabular}{cccc}
\hline No & $\begin{array}{c}\text { Kriteria Penulisan } \\
\text { Diagnosis }\end{array}$ & $(\Sigma)$ & $\mathbf{( \% )}$ \\
\hline 1. & $\begin{array}{c}\text { Sesuai (Sama) } \\
\text { Tidak sesuai } \\
\text { (berbeda) }\end{array}$ & 77 kasus & $93,9 \%$ \\
& 5 kasus & $6,1 \%$ \\
\hline & $\sum$ Total & 82 kasus & $100 \%$ \\
\hline
\end{tabular}

Tabel 4 Distribusi Usia Pasien dengan

Perbedaan Penulisan Diagnosis Gastroenteritis pada Formulir Ringkasan Masuk Keluar dan Ringkasan Pulang

\begin{tabular}{|c|c|c|c|}
\hline No & $\begin{array}{l}\text { Usia } \\
\text { Pasien }\end{array}$ & $\begin{array}{c}\text { Formulir } \\
\text { Ringkasan } \\
\text { Masuk Keluar } \\
\end{array}$ & $\begin{array}{l}\text { Formulir } \\
\text { Ringkasan } \\
\text { Pulang } \\
\end{array}$ \\
\hline 1. & $\geq 15$ tahun & GE, Ca. Rectum & Ca. Recti \\
\hline 2. & $\geq 15$ tahun & $\begin{array}{l}\text { GEA Dehidrasi } \\
\text { Sedang, Disentri }\end{array}$ & $\begin{array}{l}\text { GEA } \\
\text { Dehidrasi } \\
\text { Sedang }\end{array}$ \\
\hline 3. & $\begin{array}{l}1 \text { tahun }-4 \\
\text { tahun }\end{array}$ & DCA Disentri & $\begin{array}{l}\text { Diare Cair } \\
\text { Akut }\end{array}$ \\
\hline 4. & $\geq 15$ tahun & $\begin{array}{l}\text { Disentri, Anemia } \\
\text { Hemoroids }\end{array}$ & $\begin{array}{l}\text { Disentri, } \\
\text { Anemia }\end{array}$ \\
\hline 5. & $\begin{array}{l}1 \text { tahun }-4 \\
\text { tahun }\end{array}$ & $\begin{array}{c}\text { Diare Cair Akut } \\
\text { Dehidrasi Sedang } \\
\text { (ada amoeba) }\end{array}$ & $\begin{array}{l}\text { Diare Cair } \\
\text { Akut }\end{array}$ \\
\hline
\end{tabular}

Dari hasil analisa ketidaksesuaian antara lembar formulir ringkasan masuk keluar dan ringkasan pulang didapatkan penulisan diagnosis terbanyak yang tidak sesuai pada rekam medis pasien usia $\geq 15$ tahun yang dilakukan penulisan diagnosis oleh Dokter Spesialis Penyakit Dalam.

Adapaun ketidaksesuaian penulisan diagnosis tersebut dikarenakan terdapat penulisan diagnosis yang tidak lengkap dan tidak konsisten antara lembar formulir ringkasan masuk keluar dan ringkasan pulang, dan terdapat penulisan singkatan diagnosis yang tidak konsisten pada diagnosis penyakit gastroenteritis pasien

Penulisan diagnosis yang berbeda atau tidak lengkap ini akan mempengaruhi pada hasil pengkodean yang akan dilakukan oleh coder sehingga akan berpengaruh pada analisa data pelaporan rumah sakit dan terutama akan berpengaruh dalam sistem pembiayaan pelayanan kesehatan oleh BPJS kepada rumah sakit.
Oleh karena itu, isi formulir ringkasan masuk keluar dan ringkasan pulang harus saling berkaitan sesuai dan lengkap agar memudahkan dokter dalam memberikan pengobatan kembali kepada pasien sehingga pasien mengetahui riwayat penyakitnya secara jelas dan runtut.

\section{b. Ketepatan Pemberian Kode Penyakit Gastroenteritis}

Dari 82 sampel rekam medis pasien BPJS rawat inap penyakit gastroenteritis pada tahun 2017 , terdapat 7 kode diagnosis gastroenteritis yang tidak tepat dan 75 kode diagnosis gastroenteritis yang tepat dengan persentase ketepatan pemberian kode diagnosis penyakit gastroenteritis pasien BPJS rawat inap di UPTD RSUD Kota Salatiga sebagai berikut :

Tabel 5 Ketepatan Pemberian Kode

Penyakit Gastroenteritis Pada Lembar Formulir Ringkasan Masuk Keluar (RMK)

\begin{tabular}{lccc}
\hline No & $\begin{array}{c}\text { Ketepatan Pemberian } \\
\text { Kode RMK }\end{array}$ & $\mathbf{( \Sigma )}$ & $\mathbf{( \% )}$ \\
\hline 1. & Tepat (Sesuai) & 75 kasus & $91,5 \%$ \\
2. & Tidak Tepat & 7 kasus & $8,5 \%$ \\
\hline & $\sum$ Total & 82 kasus & $100 \%$ \\
\hline
\end{tabular}

Sumber : Data Primer Rekam Medis Pasien Gastroenteritis

Tabel 6. Ketidaktepatan Pemberian Kode dengan Diagnosis Pada Formulir

Ringkasan Masuk Keluar Maupun Pada Formulir Ringkasan Pulang

\begin{tabular}{cccc} 
No & $\begin{array}{c}\text { Diagnosis pada } \\
\text { Ringkasan Masuk Keluar } \\
\text { / pada Ringkasan Pulang }\end{array}$ & $\begin{array}{c}\text { Kode } \\
\text { Petugas }\end{array}$ & $\begin{array}{c}\text { Kode } \\
\text { Peneliti }\end{array}$ \\
\hline 1. & GEA pada Gravida 7 & A09 & O98.8 \\
Bulan & O98.8 & A09.0 \\
2. & GEA pada Gravida 7 & A09 & O98.8 \\
& Bulan & O98.8 & A09.0 \\
\hline
\end{tabular}

UPTD RSUD Kota Salatiga sudah menggunakan buku pedoman ICD-10 Versi 2010 dan berdasarkan wawancara dengan coder diketahui bahwa untuk pengkodean kasus gastroenteritis pada aplikasi BPJS dulu hanya support dengan ICD-10 Versi 2005 dengan kode gastroenteritis kode A09 saja, akan tetapi berdasarkan observasi peneliti pada aplikasi SIMRS hanya support dengan ICD-10 versi 2005 dengan kode gastroenteritis A09 saja dan aplikasi klaim BPJS sudah berganti ke versi ICD-10 versi 2010. Persentase 
ketepatan kode sebesar 91,5\% sesuai standar pengkodean jika dibandingkan dengan versi 2005 dan ketidaktepatan kode sebesar 6,1 \% dikarenakan salah dalam menentukan kode yang tepat sehingga tidak sesuai dengan standar pengkodean.

\section{c. Kesesuaian Hasil Pemeriksaan Laboratorium dengan Penulisan Diagnosis Kasus Gasroenteritis \\ Hasil penelitian di UPTD RSUD Kota} Salatiga didapatkan dari 82 sampel rekam medis pasien BPJS rawat inap penyakit gastroenteritis pada tahun 2017, terdapat 73 diagnosis pasien kasus gastroenteritis yang sesuai (lengkap) dengan hasil pemeriksaan laboratorium, 4 diagnosis pasien kasus gastroenteritis yang tidak diagnosis pasien kasus gastroenteritis yang dilakukan pemeriksaan laboratorium terdapat hasil pemeriksaan bakteri amoeba hystolitica $(+)$. Hasil tersebut setelah dilakukan pengolahan data didapatkan persentase kesesuaian hasil pemeriksaan laboratorium dengan diagnosis kasus gastroenteritis sebagai berikut:

Tabel 8. Kesesuaian Hasil Pemeriksaan

Laboratorium Dengan Diagnosis Kasus

Gastroenteritis UPTD RSUD Kota Salatiga

\begin{tabular}{|c|c|c|c|}
\hline No & $\begin{array}{l}\text { Kesesuaian Diagnosis } \\
\text { dengan Hasil Lab }\end{array}$ & $\left(\sum\right)$ & $(\%)$ \\
\hline 1. & Sesuai & 73 kasus & $89 \%$ \\
\hline 2. & $\begin{array}{l}\text { Tidak sesuai (Bakteri } \\
\text { Amoeba Hystolitica (+)) }\end{array}$ & 5 kasus & $6,1 \%$ \\
\hline 3. & $\begin{array}{l}\text { Tidak ada pemeriksaan } \\
\text { laboratorium }\end{array}$ & 4 kasus & $4,9 \%$ \\
\hline \multicolumn{2}{|r|}{ Jumlah Total } & 82 kasus & $100 \%$ \\
\hline
\end{tabular}

Menurut buku panduan praktik klinis bagi dokter bahwa untuk penyakit gastroenteritis dilakukan pemeriksaan penunjang atau laboratorium misalnya mencakup :

1) Pemeriksaaan tinja

Makroskopis dan mikroskopis, ph dan kadar gula dalam tinja, dan resistensi feces (colok dubur)

Analisa gas darah apabila didapatkan tanda-tanda gangguan keseimbangan asam basa (pernafasan kusmaul).
2) Pemeriksaan kadar ureum dan keratin untuk mengetahui faal ginjal

3) Pemeriksaan elektrolit terutama kadar $\mathrm{Na}, \mathrm{K}$, Kalsium dan posfat.

Menurut Peraturan Menteri Kesehatan No. 269 Tahun 2008 Tentang Rekam Medis bahwa Indikator Mutu Rekam Medis mencakup beberapa indikator salah satunya yaitu indikator kelengkapan isian rekam medis penunjang medis dan diagnosis.

\section{d. Faktor-faktor yang Mempengaruhi Hasil Pengkodean Penyakit Gastroenteritis}

Faktor pertama yang mempengaruhi hasil pengkodean penyakit yang dilakukan coder adalah tenaga medis sebagai pemberi pelayanan kesehatan dalam menetapkan diagnosis pasien Berdasarkan tabel 4.3 dan tabel 4.4 menunjukkan terdapat perbedaan penulisan diagnosis sebanyak 5 kasus dengan ini petugas coder belum melakukan evaluasi dan review terhadap rekam medis pasien gastroenteritis.

Faktor kedua yang mempengaruhi hasil pengkodean penyakit yang dilakukan coder adalah tidak melihat hasil pemeriksaan penunjang untuk menentukan kode yang tepat. Berdasarkan tabel 4.7 menunjukkan bahwa ketidaktepatan pemberian kode dikarenakan ketidaksesuaian penulisan diagnosis dengan hasil pemeriksaan laboratorium.

Faktor ketiga yang mempengaruhi hasil pengkodean penyakit yang dilakukan coder adalah kurang mengupdate buku pedoman koding WHO.

\section{Simpulan dan Saran}

\section{a. Simpulan}

Berdasarkan hasil dan pembahasan diatas dapat ditarik simpulan bahwa :

1) Persentase kesesuaian penulisan diagnosis gastroenteritis pada lembar formulir ringkasan masuk keluar dan ringkasan pulang sebesar 93,9 \%, sedangkan persentase ketidaksesuaian antara lembar formulir ringkasan masuk keluar dan ringkasan pulang sebesar $6,1 \%$.

2) Persentase ketepatan pemberian kode diagnosis gastroenteritis sebesar 91,5 $\%$, sedangkan ketidaktepatan 
pemberian kode diagnosis gastroenteritis sebesar $8,5 \%$.

3) Dari total sampel diperoleh persentase kesesuaian hasil pemeriksaan laboratorium dengan diagnosis kasus Gatroenteritis sebesar $89 \%$, ketidaksesuaian hasil pemeriksaan laboratorium dengan diagnosis sebesar 6,1 $\%$, dan tidak ada hasil pemeriksaan laboratorium sebesar 4,9\%.

4) Faktor-faktor yang mempengaruhi hasil koding gastroenteritis yaitu tenaga medis (dokter) menuliskan diagnosis gastroenteritis pasien secara tidak lengkap dan tidak sesuai antar lembar formulir, coder tidak mengecek hasil pemeriksaan penunjang (laboratorium) untuk menentukan kode yang tepat, kurangnya kegiatan update koding ICD-10 Versi 2010.

\section{b. Saran}

1) Petugas koding (PMIK) selalu melakukan update koding berdasarkan ICD-10 Versi terbaru.

2) Petugas coding melakukan pengembangan keilmuan yang berhubungan audit coding dengan hasil pemeriksaan laboratorium.

3) Jika rumah sakit mengadakan kegiatan audit klinis dengan dokter sebaiknya mengikut sertakan PMIK.

4) Meningkatkan komunikasi dan kolaborasi coder dengan bagian pengelolaan klaim.

5) Sebaikanya mensosialisasikan kepada dokter mengenai pentingnya menulisakan diagnosis pasien dengan lengkap.

\section{Ucapan Terimakasih}

Dalam penyusunan karya tulis ilmiah penulis banyak mendapat saran, kritik, dorongan, bimbingan serta keteranganketerangan dari banyak pihak, yang menjadikan penulis dapat menyusun karya tulis ini dengan baik dan dapat dipertanggungjawabkan. Oleh karena itu dengan segala hormat dan kerendahan hati perkenankan penulis mengucapkan terimakasih untuk seluruh pihak yang terlibat dalam penyusunan karya tulis ilmiah ini.

\section{Daftar Pusataka}

Aru W, Sudoyo. (2009). Buku Ajar Ilmu Penyakit Dalam. Jakarta : Interna Publishing.

Digdowirogo, Hadjat S, dkk. (2014). Panduan Praktik Klinis Bagi Dokter. (Online), (Http://Fk.Unila.ac.id, diakses 3 Maret 2018).

Spesialis (2010). Pedoman Praktik Dokter http://spesialis1.ika.fk.unair.ac.id/wpcontent / uploads2017/03/Pedoman-PraktikDokter-Spesialis-Anak.pdf. Diakses tanggal 24 April 2018.

Hatta, Gemala R. (2013). Pedoman Manajemen Informasi Kesehatan Disarana Pelayanan Kesehatan. Jakarta : Ui-Press.

Kementrian Kesehatan Republik Indonesia. (2011). Health Statistics. (online) http://www.depkes.go.id/resources/downlo ad/pusdatin/profilkesehatan/profil-

kesehatan-indonesia 2011.pdf. Diakses tanggal 20 April 2018.Jakarta : Kementrian Kesehatan RI.

Keputusan Menteri Kesehatan RI No 377/Menkes/Sk/Iii/2007 Tentang Standar Profesi Perekam Medis Dan Informasi Kesehatan.2007.Jakarta : Menkes RI.

Kresnowati, Lily dan Ernawati. (2012). Analisis Faktor-Faktor Yang Mempengaruhi Akurasi Koding Diagnosis Dan Prosedur Medis Pada Dokumen Rekam Medis Di Rumah Sakit Kota Semarang. Semarang : Program Studi Rekam Medis dan Informasi Kesehatan, Universitas Dian Nuswantoro.

Komisi Akreditasi Rumah Sakit. (2017). Standar Nasional Akreditasi Rumah Sakit Edisi I (Online).(http://www.pdpersi.co.id/kanalpersi/ma najemen_mutu/data/snars_edisi1.pdf, diakses tanggal 25 April 2018).

Nani. BAB 1 PENDAHULUAN. (http:/ / eprints.undip.ac.id/32688/1/1.pdf, diakses tanggal 27 April 2018).

Notoatmodjo, Soekidjo. (2010). Metodologi Penelitian Kesehatan. Jakarta : Rineka Cipta.

Peraturan Menteri Kesehatan Republik Indonesia Nomor 76 Tahun 2016 Tentang Pedoman Indonesia Case Base Groups (INA-CBG) Dalam Pelaksanaan Jaminan Kesehatan Nasional.2016. Jakarta : Menkes RI.

Peraturan Menteri Kesehatan Republik Indonesia Nomor 5 Tahun 2014 Tentang

Panduan Praktis Klinis (PPK) Bagi Dokter Di Fasilitas Pelayanan Kesehatan Primer. 2014. Jakarta :Menkes RI. 
Peraturan Menteri Kesehatan Republik Indonesia Nomor 269 / Menkes / Per / III/ 2008 Tentang Rekam Medis. 2008. Jakarta : Menkes RI.

Peraturan Menteri Kesehatan Republik Indonesia Nomor 55 Tahun 2013 Tentang Penyelenggaraan Pekerjaan Perekam Medis. Jakarta : Menkes RI. 